\title{
Acute neuropsychiatric disorders in adolescents and young adults with Down syndrome: Japanese case reports
}

This article was published in the following Dove Press journal:

Neuropsychiatric Disease and Treatment

27 July 2012

Number of times this article has been viewed

\author{
Keiko Akahoshi' \\ Hiroshi Matsuda ${ }^{2}$ \\ Masuko Funahashi' \\ Tomoyuki Hanaoka ${ }^{3}$ \\ Yasuyuki Suzuki' \\ 'Department of Pediatrics, Tokyo \\ Children's Rehabilitation Hospital, \\ Tokyo; ${ }^{2}$ Department of Nuclear \\ Medicine, Saitama Medical University, \\ International Medical Center, Saitama; \\ ${ }^{3}$ Department of Pediatrics, Bihoro \\ Rehabilitation Hospital, Hokkaido, \\ Japan
}

Background: The aim of this study was to evaluate acute neuropsychiatric disorders in adolescents and young adults with Down syndrome. We report 13 Japanese adolescents or young adults with Down syndrome who developed acute neuropsychiatric disorders including withdrawal, depression, obsessive-compulsive behaviors, and occasional delusions or hallucinations.

Methods: The following information was collected from each patient: age at onset of acute neuropsychiatric disorder, complications, signs and symptoms, personality traits before the onset of the acute neuropsychiatric disorder, prescribed medications with their respective doses and the response to treatment, and senile changes observed on magnetic resonance imaging or computed tomography.

Results: The mean age at onset of these disorders was 21.2 years. Brain imaging showed almost senile changes; patients responded well to low-dose psychotropic therapy. Patients had an onset at a young age and presented with treatable conditions, although the average age of the onset of Alzheimer's disease is generally over 40 years of age in patients with Down syndrome.

Conclusion: These findings suggest that the pathology of acute neuropsychiatric disorder in patients with Down syndrome may be related to presenile changes; however, these disorders present features and a clinical course that is different from those presented in typical Alzheimer's disease with Down syndrome.

Keywords: Down syndrome, acute neuropsychiatric disorders, Alzheimer's disease

\section{Introduction}

Psychiatric disorders exhibit a prevalence of 20\%-30\% in individuals with Down syndrome. ${ }^{1,2}$ Two major types of psychiatric disorders occur throughout the lives of individuals with Down syndrome. Autism spectrum disorders and attentiondeficit/hyperactivity disorders, including behaviors such as obstinacy, obsessiveness, stubbornness, hyperactivity, self-damage, abuse, panic, and conduct disturbances, typically occur during childhood and youth. ${ }^{3,4}$ Kent et al indicated that $7 \%$ of children with Down syndrome may present with autism spectrum disorders. ${ }^{5}$ In addition, cognitive disorder is a feature of Alzheimer's disease that presents at approximately 40 years of age in individuals with Down syndrome. ${ }^{6}$ Coppus et al noted that the overall prevalence of dementia is $16.8 \%$ in individuals with Down syndrome. ${ }^{7}$

Another psychiatric disorder in addition to the two stated above is also observed. Some individuals with good premorbid function develop acute neuropsychiatric disorders as adolescents or young adults. Their symptoms include psychomotor slowness, withdrawal, mutism, apathy, emotional instability, anorexia, insomnia,
Correspondence: Keiko Akahoshi

Tokyo Children's Rehabilitation Hospital, 4-I0-I Gakuen Musashi-Murayama,

Tokyo, 208-00II, Japan

$\mathrm{Tel}+8|4256| 252 \mid$

Fax +81425663753

Email fwkt4I24@mb.infoweb.ne.jp 
obsessive-compulsive behaviors, and occasional delusions or hallucinations. Such individuals would be diagnosed with major depressive, obsessive-compulsive, delusional, or adjustment disorders according to the diagnosed criteria. ${ }^{8-11}$ Capone et al noted that psychiatric disorders in adolescents or young adults with Down syndrome are not inextricably linked to cognitive impairment and are treatable. ${ }^{12}$

We investigated for the presence of acute neuropsychiatric disorders in Down syndrome outpatients at Tokyo Children's Rehabilitation Hospital by reviewing their medical records for the previous 10 years. We report the clinical course and brain magnetic resonance imaging (MRI) or computed tomography (CT) findings for 13 Japanese individuals with Down syndrome who developed an acute neuropsychiatric disorder.

\section{Materials and methods}

\section{Participants}

All patients with Down syndrome at the outpatient facility of our hospital who were more than 10 years of age and presented with an acute psychiatric disorder, with the exception of autism spectrum disorders or dementia, during the 10-year period from January 1999 to December 2008 were studied. Subjects were diagnosed on the basis of the criteria provided in the Diagnostic and Statistical Manual of Mental Disorders, Fourth Edition. The subjects included six male and seven female patients with trisomy 21 . The following information was collected from each patient: age at onset of the acute neuropsychiatric disorder, complications, signs and symptoms, personality traits before the onset of the acute neuropsychiatric disorder (based on parental reports), prescribed medications with their respective doses and response to treatment (assessment conducted within 2 years of onset of the acute neuropsychiatric disorder), and senile changes observed on MRI or CT.

\section{Case reports}

A summary of the findings of these 13 subjects is presented in Table 1. We describe the clinical courses of cases 1-5, whose intracranial findings were available. These patients underwent MRI or CT study soon after they visited our hospital.

\section{Case I}

This was a girl who responded to a single dose of medication. She was described as mild, tidy, precise, obstinate, and active. She took piano and ballet lessons and helped with the household chores. At the age of 10 years and 5 months, she suddenly became inactive, silent, and neglected a diary that she had been writing in daily. She stopped getting out of bed and did not watch television or the videos that she had previously enjoyed watching. She was expressionless, unkempt, repeated stereotypic behaviors, laughed to herself, and developed insomnia.

After 3 months, she was brought to our hospital by her family and was diagnosed with major depressive disorder not otherwise specified. Her symptoms disappeared one week after premedication with chlorpromazine $25 \mathrm{mg}$, phenobarbital $40 \mathrm{mg}$, and promethazine $12.5 \mathrm{mg}$, which were administered before she underwent brain MRI. She remitted before beginning antidepressants that were prescribed at a subsequent visit to the hospital. She returned to a good mental state and level of activity. However, MRI findings revealed marked areas of low signal intensity in the pallidum and an area of slightly high signal intensity in the pyramidal tract (Figure 1A).

\section{Case 2}

This was a woman with depression who responded well to a selective serotonin reuptake inhibitor. She was described as cheerful and precise and had been maintaining a diary that she had written in every day for 10 years. She never missed school and was a member of the basketball and softball teams. After graduating from school, she worked in a home for the aged, taking care of the elderly. She was taking piano lessons, learning to perform the Japanese tea ceremony, and enjoyed writing. At the age of 29 years, she became lethargic, depressed, and frequently needed to rest at work. After 2 months, she became withdrawn and could no longer go to work, eat, or bathe herself. She would lie in bed, sobbing and complaining, "I am hopeless and tired". She felt discomfort in her chest and developed irregular menstruation. At the same time, she was diagnosed with cataracts. She visited our hospital at the age of 30 years (7 months after the onset of her symptoms) and was diagnosed with major depressive disorder. MRI findings showed atrophy of the hippocampus and diffuse mild ischemic changes in the cerebral white matter (Figure 1B). The patient's psychomotor slowness and depressed mood improved 3 months after treatment with a selective serotonin reuptake inhibitor (fluvoxamine $12.5 \mathrm{mg}$ /day). Her symptoms resolved and she quickly became cheerful, optimistic, and resumed eating by the age of 31 years.

\section{Case 3}

This was a woman with an acute neuropsychiatric disorder and a thyroid disorder. The patient was described as cheerful, active, 


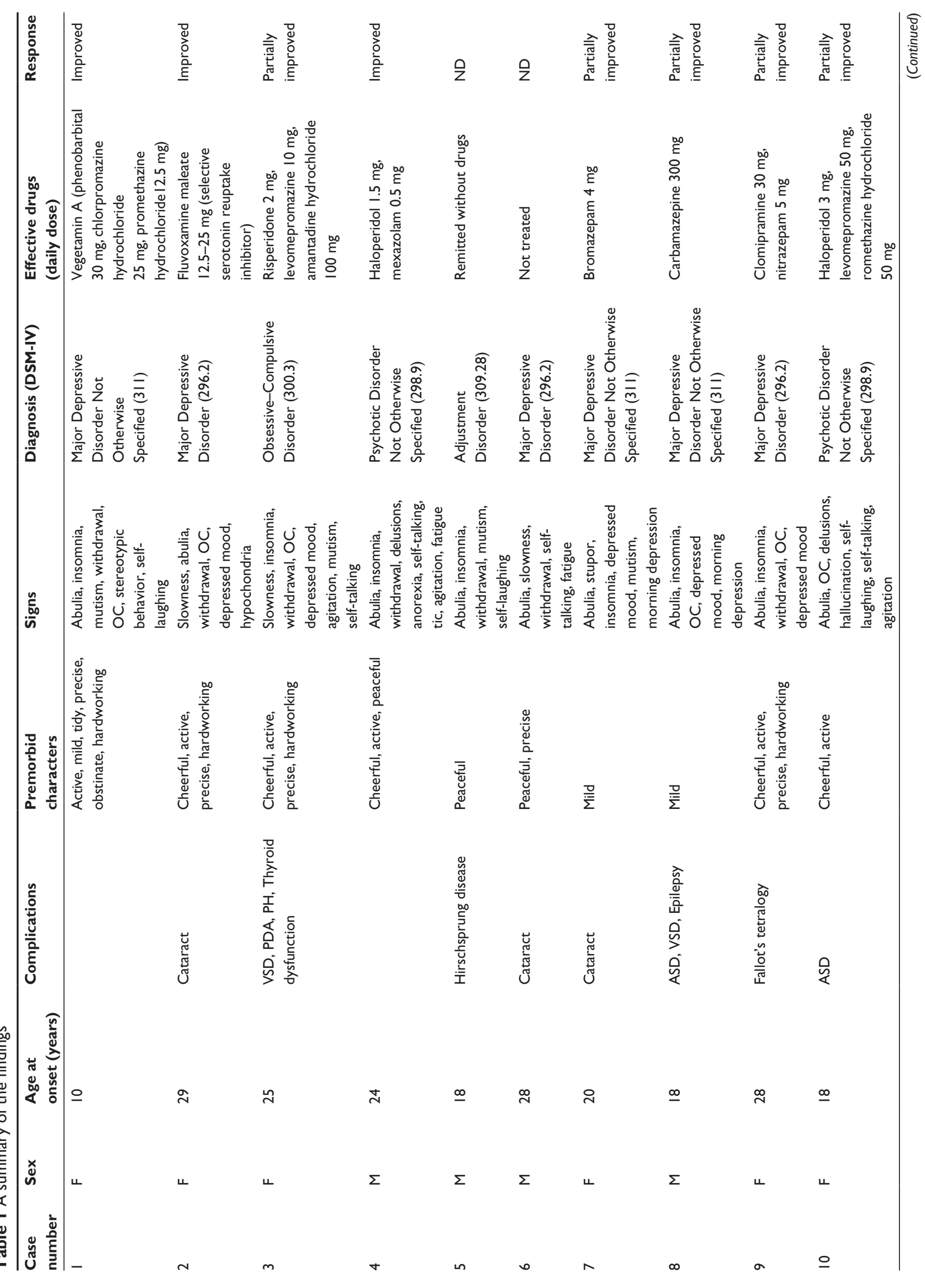




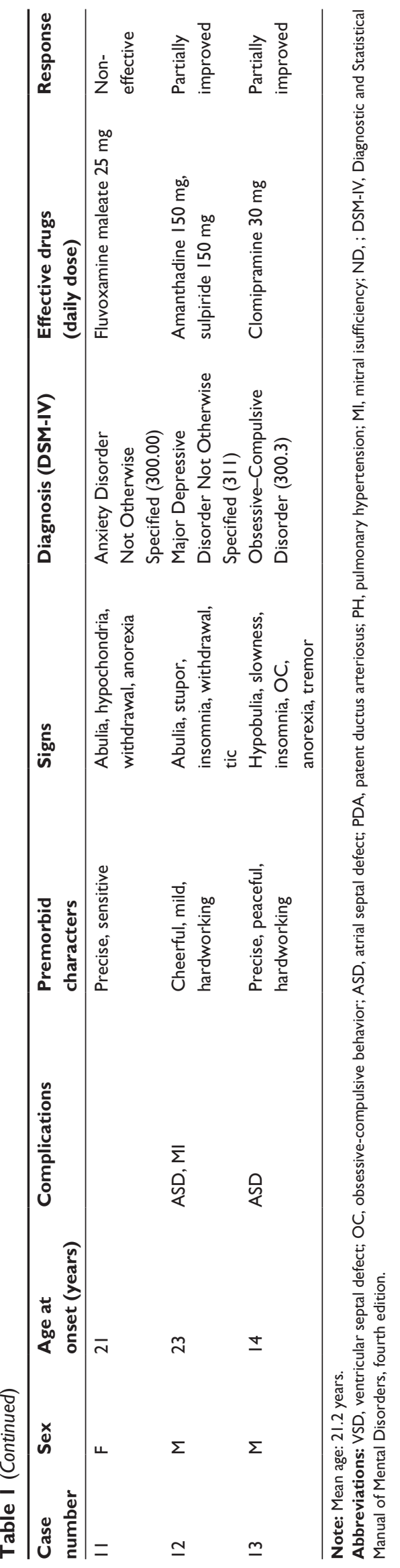

and precise in nature. After graduating from a special school, she was employed at a workshop for the handicapped. At the age of 25 years, she developed insomnia, sluggish movements, and obsessive-compulsive behavior (repeatedly washing her hands and face). She remained silent or talked to herself and refused to go to work. She became short-tempered and manifested repeated stereotypic behavior. She visited our hospital at the age of 26 years and was diagnosed with obsessive-compulsive disorder. Examinations revealed hyperthyroidism and she was treated with thiamazole (doses up to $50 \mathrm{mg} /$ day) for a year. Although her hyperthyroidism improved, her psychiatric condition remained unchanged. After administration of risperidone $2 \mathrm{mg} /$ day, amantadine $100 \mathrm{mg} /$ day, and levomepromazine $10 \mathrm{mg} /$ day for 2 days, her sleep disturbances and sluggish movements improved, and she returned to her normal daily routine. Her obsessive-compulsive behavior partially improved. An intracranial CT examination at the age of 28 years revealed calcification of the pallidum, pineal body, and habenular commissure (Figure 1C).

\section{Case 4}

This was a man whose delusional state improved with psychotropic therapy. He was described as having a cheerful and peaceful disposition and worked as a painter after graduating from high school. At the age of 24 years, he watched a news broadcast and mistakenly thought that his favorite announcer had been killed. He began to stay indoors, stopped eating and bathing, and remained in bed. He suffered from insomnia and began talking to himself. Furthermore, he occasionally showed panic, facial tics, adopted a fighting pose, and shouted. He complained of fatigue and displayed psychomotor slowness. At the age of 26 years, he visited our hospital with his family and was diagnosed with psychotic disorder not otherwise specified. MRI showed hippocampal atrophy, marked areas of low signal intensity in the pallidum and increased signal intensity in the decussation of the superior cerebellar peduncles (Figure 1D).

Despite treatment with a selective serotonin reuptake inhibitor (fluvoxamine $10-20 \mathrm{mg}$ /day) for 3 months, the patient's condition did not improve and he frequently talked to himself. However, after one month of treatment with haloperidol $1.5 \mathrm{mg} /$ day and mexazolam $0.5 \mathrm{mg} /$ day, he showed improvement and was able to hold a conversation.

\section{Case 5}

This was a man whose condition improved without drugs. The patient was described as having a peaceful disposition. At the age of 18 years, he graduated from a school for 

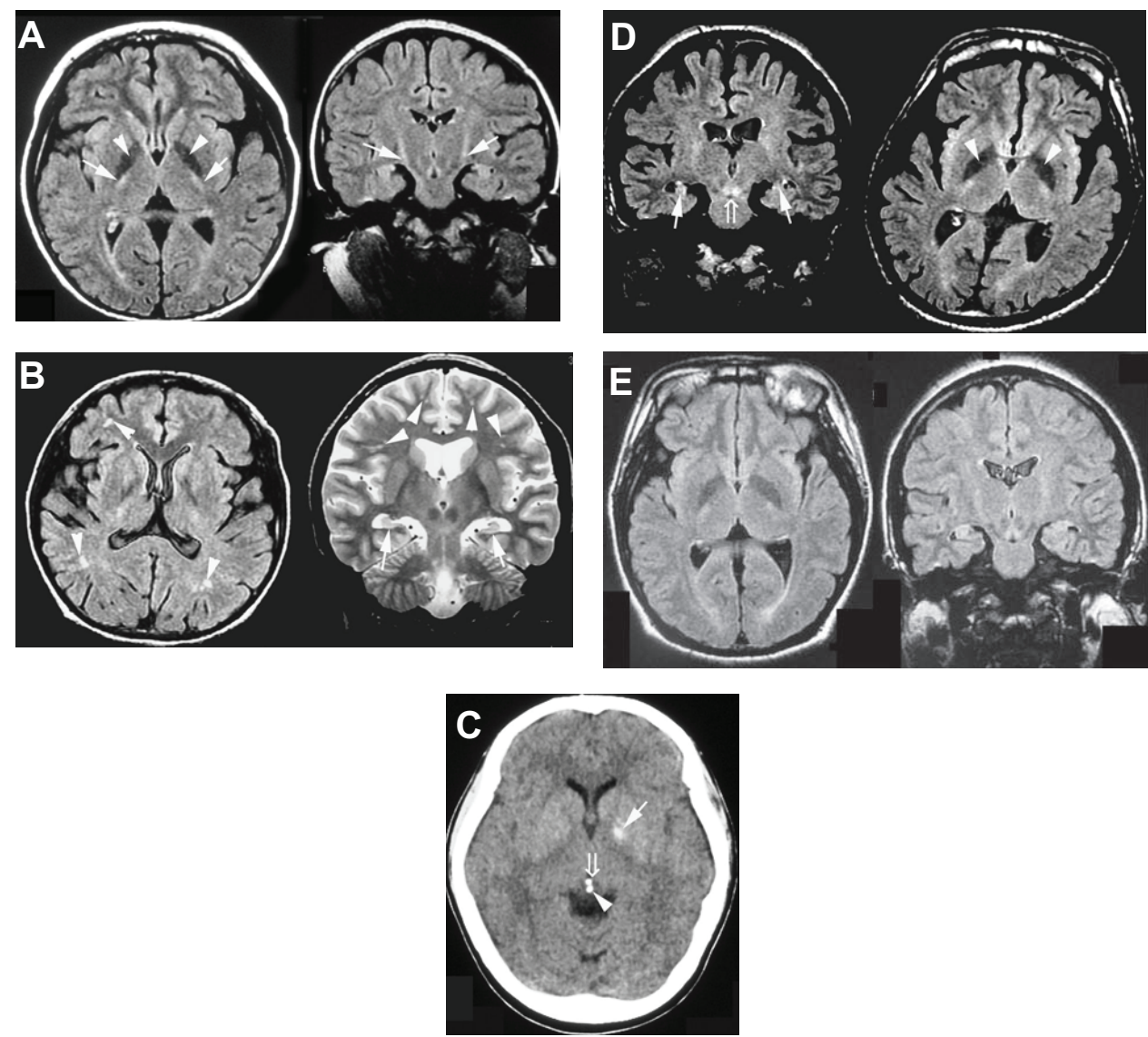

Figure I (A) FLAIR sequence of brain MRI at the age of 10 years (Case I). The patient showed marked areas of low signal intensity in the pallidum (arrowhead) and areas of slightly high signal intensity in the pyramidal tract (arrow). (B) FLAIR and T2-weighted sequences of MRI at the age of 30 years (Case 2). The patient showed hippocampal atrophy (arrow) and diffuse mild ischemic changes in the cerebral white matter (arrowhead). (C) CT scan at the age of 28 years (Case 3). The patient showed calcification of the pallidum (arrow), pineal body (arrowhead), and habenular commissure (open arrow). (D) FLAIR sequences of MRI at the age of 26 years (Case 4). The patient showed hippocampal atrophy (arrow), marked areas of low signal intensity in the pallidum (arrowhead), and areas of increased signal intensity in the decussation of the superior cerebellar peduncles (open arrow). (E) FLAIR sequences of MRI at the age of I 8 years (Case 5). The patient showed hippocampal atrophy.

Abbreviations: FLAIR, fluid-attenuated inversion recovery; MRI, magnetic resonance imaging; CT, computed tomography.

handicapped children and began to work with the disabled. After one month, he suddenly became inactive and silent, lost his appetite, and developed insomnia. He developed abulia, withdrawal, and started laughing to himself. His mother and his work supervisors reported that there were no problems with his work. He was immediately brought to our hospital by his family and diagnosed with adjustment disorder. MRI findings showed hippocampal atrophy (Figure 1E). One month after he was admitted, his symptoms disappeared without medication, and he was able to return to work.

\section{Results}

The findings from these 13 subjects are given in Table 1. The mean age of onset of acute neuropsychiatric disorder was 21.2 (range 10-29) years of age. A review of their premorbid personalities, as stated in family reports, indicated that these individuals were cheerful (46\%), active (46\%), precise
(54\%), hardworking (46\%), and mild or peaceful (54\%). The following psychiatric features were noted: psychomotor slowness (abulia or hypobulia) occurring in all 13 subjects, with two presenting with stupor (catatonia). Insomnia occurred in nine patients (69\%). Withdrawal (69\%) and round-the-clock insomnia were conspicuous features.

Obsessive-compulsive behavior presented in seven cases $(54 \%)$ and was more resistant to medication. Delusions and/or hallucinations occurred in two cases (15\%). Although, in individuals with Down syndrome, self-talking and self-laughing under their fantasy world are common, in individuals with acute neuropsychiatric disorders, the same behaviors were observed with underlying anxiety, delusions or hallucinations $(46 \%)$. Eleven of the 13 patients agreed to receive pharmacological therapy; three showed marked improvement (27\%), seven responded to treatment (64\%), and one did not respond to treatment (9\%). All psychotropic drugs were used in low doses. 


\section{Discussion}

There are accumulated reports about autism spectrum disorders and attention-deficit hyperactivity disorders during childhood and Alzheimer's disease in adults aged 40 years or older with Down syndrome..$^{3-7}$ Recently, the existence of a third psychiatric disorder with Down syndrome has been discussed in several academic societies concerned with Down syndrome in different countries, including Japan and the UK. Patients with these conditions show psychiatric symptoms with acute progress, and are affected at an early age; further, these are frequently reversible conditions. They are referred to as "acute regression of Down syndrome in young adults" in Japan. However, these conditions have not been reported. Acute neuropsychiatric disorders are a new concept and diagnosed criteria have not been established. We investigated cases of acute neuropsychiatric disorders in our hospital. As a result, these Down syndrome patients with acute neuropsychiatric disorders showed psychiatric symptoms, and their intracranial examinations revealed some senile changes.

Bipolar disorder and schizophrenia seem to be relatively uncommon in individuals with Down syndrome. ${ }^{13}$ However, several psychiatric-like symptoms, such as depressive mood, manic episodes, obsessive-compulsive behaviors, paranoia, and maladaptive impairment, have been reported in patients with Down syndrome..$^{9,14-17}$ The individuals with Down syndrome we studied also presented with these features.

Meanwhile, intracranial senile changes are known to appear at an early age in individuals with Down syndrome. Wisniewski et al found that Alzheimer's disease-like pathological changes (eg, neuronal loss, neurofibrillary tangles, or plaques) occurred after 35 years of age in a majority of individuals and that basal ganglia calcification was common in such individuals. ${ }^{18,19}$ Individuals whom we studied showed senile changes in those younger than 30 years of age. In brain imaging studies (MRI or CT) of cases 1-5, almost all showed some senile changes (eg, ischemic changes of the cerebral white matter, hippocampal atrophy, or basal ganglia calcification). Such senile changes were even found in a patient as young as 10 years of age (Figure 1A). Furthermore, cataract (a senile complication) was detected in three patients $(23 \%)$ and subjects had a higher than normal incidence (15\%) of complications associated with Down syndrome (according to the health guidelines for children with Down syndrome, American Academy of Pediatrics Committee) ${ }^{20}$ These findings suggest that acute neuropsychiatric disorders may be biologically related to some form of senility.
Typical Alzheimer's disease in individuals with Down syndrome occur at approximately 40 years of age and older. ${ }^{21,22}$ Tyrrell et al reported that dementia in individuals with Down syndrome occurs at a mean age of 54.7 years ${ }^{23}$ and Visser et al reported 56 years as the mean age of onset; ${ }^{24}$ however, the average age of onset of acute neuropsychiatric disorders among the patients described here was 21.2 years, indicating that the age of onset for acute neuropsychiatric disorder is lower than that for typical Alzheimer's disease in individuals with Down syndrome. Further, the clinical features of dementia in individuals with Alzheimer's disease and Down syndrome are similar to those of Alzheimer's disease in the general population. Down syndrome patients with dementia also show loss of memory, cognitive decline, changes in adaptive behavior, neurological changes, and language difficulties; ${ }^{25,26}$ these symptoms are progressive (not reversible). ${ }^{27}$ In contrast, the clinical features of individuals with acute neuropsychiatric disorders appear to be more similar to those of individuals with psychiatric illnesses, such as major depressive and obsessivecompulsive disorder or schizophrenia (Table 1). The signs of an acute neuropsychiatric disorder include withdrawal into the bathroom, repeated face washing, mutism, depressive mood, decreased appetite, insomnia, and occasional delusions or hallucinations. Furthermore, low doses of psychotropic drugs were effective in the treatment of our patients with acute neuropsychiatric disorder. Thus, although these patients showed senile changes, their symptoms and courses differed from those with typical Alzheimer's disease with Down syndrome. Aylward et al stated that behavioral changes such as withdrawal and apathy appear to be early signs of dementia and that the course of Alzheimer's disease and these conditions are related to frontal lobe dysfunction and are characterized by the frequent occurrence of neurological disorders such as early-onset Alzheimer's disease-type dementia. ${ }^{27-30}$ It has recently been demonstrated by Kondoh et al that donepezil, a drug often used in patients with Alzheimer's disease, improves the activities of daily living in Down syndrome patients, including young adults with the abovementioned rapid and progressive deterioration of such activities. ${ }^{31}$ The latter report suggests that individuals with Down syndrome and acute neuropsychiatric disorder may respond favorably to medication with a drug (donepezil) used in patients with Alzheimer's disease.

Our report was a retrospective study, and further prospective studies of other cases are required. Most individuals do not visit the pediatric hospital after reaching adolescence; therefore, it is not possible to assess their condition during adulthood. We recommend that individuals with Down 
syndrome be followed up routinely after puberty because adequate intervention may improve quality of life for these individuals after the age of 20 years.

\section{Disclosure}

The authors report no conflicts of interest in this work.

\section{References}

1. Myers BA, Pueshchel SM. Psychiatric disorders in persons with Down syndrome. J Nerv Ment Dis. 1991;179:609-613.

2. Prasher VP. Prevalence of psychiatric disorders in adults with Down syndrome and dementia. Eur J Psychiatry. 1995;9:77-82.

3. Gath A, Gumley D. Behavior problems in retarded children with special reference to Down's syndrome. Br J Psychiatry. 1986;149:156-161.

4. Capone GT, Grados MA, Kaufmann WE, Bernad-Ripoll S, Jewell A. Down syndrome and comorbid autism-spectrum disorder: Characterization using the aberrant behavior checklist. Am J Med Genet Part A. 2005;134:373-380.

5. Kent L, Evans J, Paul M, Sharp M. Comorbidity of autistic spectrum disorders in children with Down syndrome. Dev Med Child Neurol. 1999;41:153-158.

6. Wisniewski KE, Dalton AJ, McLachlan C, Wen GY, Wisniewski HM. Alzheimer's disease in Down's syndrome: clinicopathologic studies. Neurology. 1985;35:957-961.

7. Coppus A, Evenhuis H, Verberne GJ, et al. Dementia and mortality in persons with Down's syndrome. $J$ Intellect Disabil Res. 2006;50: 768-777.

8. Cooper SA, Collacott RA. Clinical features and diagnostic criteria of depression in Down syndrome. Br J Psychiatry. 1994;165:399-403.

9. Myers BA, Pueshchel SM. Major depression in a small group of adults with Down syndrome. Res Dev Disabil. 1995;16:285-299.

10. Cooper SA, Prasher VP. Maladaptive behaviors and symptoms of dementia in adults with Down's syndrome. $J$ Intellect Disabil Res. 1998;42:293-300.

11. Charlot L. Obsessional slowness in Down syndrome: Severe variant of OCD or separate disorder? Mental Health Aspects Dev Disabil. 2002;5:53-56.

12. Capone G, Goyal P, Ares W, Lannigan E. Neurobehavioral disorders in children, adolescents, and young adults with Down syndrome. $\mathrm{Am}$ J Med Genet C Semin Med Genet. 2006;142C:158-172.

13. Craddock N, Owen M. Is there an inverse relationship between Down's syndrome and bipolar affective disorder? Literature review and genetic implications. J Intellect Disabil Res. 1994;38:613-620.

14. Cooper SA, Collacott RA. Manic episodes in Down's syndrome. J Nerv Ment Dis. 1991;179:635-636.

15. Collacott RA, Cooper SA. Adaptive behavior after depressive illness in Down's syndrome. J Nerv Ment Dis. 1992;180:468-470.
16. Cooper SA, Collacott RA. Prognosis of depression in Down's syndrome. J Nerv Ment Dis. 1993;181:204-205.

17. O'Dwyer J, Holmes J, Collacott, RA. Two cases of obsessivecompulsive disorder in individuals with Down's syndrome. J Nerv Ment Dis. 1992;180:603-604.

18. Wisniewski KE, French JH, Rosen JF Kozlowski PB, Tenner M, Wisniewski HM. Basal ganglia calcification (BGC) in Down's syndrome - another manifestation of premature aging. Ann Neurol. 1982;396:179-189.

19. Wisniewski KE, Wisniewski HM, Wen GY. Occurrence of neuropathological changes and dementia of Alzheimer's disease in Down's syndrome. Ann Neurol. 1985;17:278-282.

20. American Academy of Pediatrcs. Committee on Genetics. Health supervision for children with Down syndrome by American Academy of Pediatrics Committee. Pediatrics. 2001;107:442-449.

21. Prasher VP, Krishnan VHR. Age of onset and duration of dementia in people with Down's syndrome: Integration of 98 reported cases in the literature. Int J Geriatr Psychiatry. 1993;8:915-922.

22. Zigman WB, Schupf N, Sersen E, Silverman W. Prevalence of dementia in adults with and without Down syndrome. Am J Ment Retard. 1996;100:403-412.

23. Tyrrell J, Cosgrave M, McCarron M, et al. Dementia in people with Down's syndrome. Int J Geriatr Psychiatry. 2001;16:1168-1174.

24. Visser FK, Aldenkamp AP, van Huffelen AC, Kuilman M, Overweg J, van Wijk J. Prospective study of the prevalence of Alzheimer-type dementia in institutionalized individuals with Down syndrome. Am J Ment Retard. 1997;101:400-412.

25. Prasher V, Filter A. Behavioral disturbance in people with Down's syndrome and dementia. J Intellect Disabil Res.1995;39:432-436.

26. Burt DB, Loveland KA, Primeaux-Hart S, et al. Dementia in adults with Down syndrome: diagnostic challenges. Am J Ment Retard. 1998;103:130-145.

27. Aylward EH, Burt DB, Thorpe LU, Lai F, Dalton A. Diagnosis of dementia in individuals with intellectual disability. $J$ Intellect Disabil Res. 1997;41:152-164.

28. Holland AJ, Hon J, Huppert FA, Stevens F. Incidence and course of dementia in people with Down's syndrome: findings from a populationbased study. J Intellect Disabil Res. 2000;44:138-146.

29. Nelson LD, Orme D, Osann K, et al. Neurological changes and emotional functioning in adults with Down syndrome. J Intellect Disabil Res. 2001;45:450-456.

30. Deb S, Hare M, Prior L. Symptoms of dementia among adults with Down's syndrome: a qualitative study. J Intellect Disabil Res. 2007;51: 726-739.

31. Kondoh T, Kanno A, Itoh H, et al. Donepezil significantly improves abilities in daily lives of female Down syndrome patients with severe cognitive impairment: a 24-week randomised, double-blind, placebocontrolled trial. Int J Psychiatry Med. 2011;41:71-89.
Neuropsychiatric Disease and Treatment

\section{Publish your work in this journal}

Neuropsychiatric Disease and Treatment is an international, peerreviewed journal of clinical therapeutics and pharmacology focusing on concise rapid reporting of clinical or pre-clinical studies on a range of neuropsychiatric and neurological disorders. This journal is indexed on PubMed Central, the 'PsycINFO' database and CAS.

\section{Dovepress}

The manuscript management system is completely online and includes a very quick and fair peer-review system, which is all easy to use. Visit http://www.dovepress.com/testimonials.php to read real quotes from published authors. 